\title{
El europeísmo español en la época de Franco y su influencia en el proceso de democratización política
}

\author{
Julio Crespo Maclennan ${ }^{*}$
}

\begin{abstract}
RESUMEN
El objetivo de este artículo es analizar

el papel del europeísmo durante el

régimen de Franco y ver la forma en

qué influye en el proceso de democratización española. A pesar del distanciamiento entre la España de

Franco y Europa occidental el europeismo desempeña un papel curical durante esta época. Para España, la Comunidad Económica

Europea es vital para razones económicas, y esto lleva a la cúpula franquista a solicitar la asociación a la CEE. Durante este periodo hay otros conceptos de europeísmo desarrollados tanto por los grupos de oposición interior y exterior, para quienes el europeísmo es simbolo de democracia.

Durante la transición el europeísmo desempeña un papel clave, ya que es uno de los pocos puntos sobre el que

\section{ABSTRACT}

The aim of this article is to analise the role of europeanism during the Franco regime and its impact on the process of Spanish democratisation. Despite the hostility between Franco's Spain and Western Europe Europeanism played a crucial role in this period. The process of European integration was vital for Spanish economic interests. This fact leads the Franco regime to apply to the European Community in 1962 and exploit europeanist rhetoric. Besides this official Europeanism there is also the Europeanism of both the domestic and the exiled opposition. For these groups europeanism simbolised democracy. During the transitiion to democracy Europeanism plays a crucial role since it is one of the very few points about which there is absolute consensus betwen all political
\end{abstract}

* St. Antony's College Oxtord. 
existe un consenso entre todos los grupos políticos desde la izquierda a la élite franquista.

\section{PALABRAS CLAVE}

El europeísmo español durante el Régimen de Franco. Visiones sobre el papel de España en la Comunidad Europea dadas por la España oficial y la oposición democrática. Influencia del debate europeísta en el proceso de democratización política. groups from the left-wing opposition to the Francoist elite.

\section{KEY WORDS}

\section{Europeanism during the Franco}

Regime. Views of Spain's role in the European Community given by official Spain and democratic opposition. Influence of the European debate on the process of political democratisation.

El europeísmo es un término utilizado con bastante frecuencia en el pensamiento político español y sin embargo existen muy pocos estudios que lo definan estrictamente y analizen su influjo en la historia de España ${ }^{1}$. Conviene por lo tanto, comenzar por aclarar su definición. Por europeísmo se entiende la idea de que España como una de las naciones fundadoras de Europa debe desempeñar un papel influyente en los asuntos continentales y a la vez seguir de cerca sus pautas de progreso en ámbitos político-culturales y socio-económicos. El término se identifica con el pensamiento político liberal predominante en el siglo diecinueve, y por lo tanto se puede considerar como una reacción al pensamiento conservador y tradicionalista español. En la segunda mitad de este siglo tiene una significación más concreta: la creencia en que España debe participar en el proceso de integración europea, que comienza poco despues del fin de la Segunda Guerra Mundial y se convierte en el eje central de la política continental tras la creación de la Comunidad Económica Europea en 1957.

Si bien la primera definición del europeísmo sigue vigente, la segunda adquiere una importancia vital durante el régimen franquista, por dos razones: en primer lugar porque el proceso de integración europea introduce en todas las naciones europeas un debate sobre cual ha de ser su relación con dicho proceso; en segundo lugar porque este proceso

José Luis ABELAN, "El significado de la idea de Europa en la política y la historia de España" y Juan Marichal, "La europeízación de España, 1931-1936", Sistema 86-87, son dos de los pocos ejemplos en el ámbito académico que tratan sobre el término europeísmo. En el ámbito político Fernándo Moran, Una política exterior para España, una alternativa socialista, Barcelona 1980 y Fernando Álvarez de Miranda, Del "contubernio" al consenso. Barcelona, 1985, analizan el crecimiento del europeísmo en la época de Franco. 
está únicamente abierto a las naciones europeas democráticas, creando así un obstáculo insuperable para la España de Franco. En este artículo examinaremos las interpretaciones dadas por diferentes grupos políticos sobre el europeísmo durante el régimen de Franco y hasta que punto influye en la opinión de que España debe convertirse en una democracia de corte occidental.

\section{LA IDEA DE EUROPA EN LA POLÍTICA ESPAÑOLA DE LA POSTGUERRA}

En un principio parece que el papel del europeísmo en la España de la post-guerra mundial es totalmente marginal. El régimen de Franco no se puede considerar como europeísta, según la definición que hemos dado al término. El franquismo se sintió inicialmente atraído por el llamado nuevo orden europeo representado por la Italia fascista y la Alemania nazi. Por lo demás, como movimiento tradicionalista tendía a considerar las influencias de Europa como conjuras masónicas que atentaban contra la esencia del espíritu español. En 1936 Franco calificó a la España forjada por los liberales del siglo diecinueve como "bastarda, afrancesada y europeízante " ${ }^{2}$.

Tras el fin de la Segunda Guerra Mundial los aliados condenaron a la España de Franco al ostracismo y vetaron su entrada en las organizaciones internacionales como la Organización Europea de Cooperación Económica, que constituye uno de los prolegómenos del movimiento de integración europea. La España franquista desafía la hostilidad de la Europa democrática, y cultiva la relación con los Estados Unidos; sin embargo, la diplomacia española saca dos conclusiones de este periodo: que las relaciones económicas con Europa son demasiado importantes como para ignorarlas y que si el proceso de integración económica europea tiene éxito España deberá esforzarse por estar en él ${ }^{3}$. Por razones económicas España no puede permitirse dar la espalda a Europa.

La primeras muestras de europeísmo en la España franquista se dieron en el mundo académico. El ex-ministro de Hacienda José Larraz, a quién más tarde se le apodaria el Jean Monnet español, debido a su entusiasmo por Europa, introdujo en los foros académicos los principales debates en

\footnotetext{
Citado por lan GiBson, En busca de José Antonio, Barcelona, 1980, pág. 314.

Para comprender la importancia de Europa para España a pesár del ostracismo ver la tesis de Fernándo Guirao, Spain and European Economic Cooperation, 1945-1955: a case study in Spanish foreign policy. Instituto Universitario Europeo, Florencia, 1993.
} 
torno al proceso de integración europea. Larraz decidió fundar la Sociedad para los Estudios Económicos Españoles, con el fín de promover el estudio sistemático del proceso de integración europea. En ella colaboraron varios expertos políticos y económicos produciendo ochenta estudios monográficos, publicados en el año 1961 bajo el título de Estudos sobre la Unificación Económica Europea. En 1949 el Instituto para Estudios Europeos y el Comité Español para la Liga Europea de Cooperación Económica fueron fundados en la Universidad de Zaragoza por el profesor Lacruz Berdejo. Publicaciones como la Revista de Estudios Políticos y la Revista de Política Internacional también prestaron atención a los inicios del proceso de integración europea. El gran filosofo José Ortega y Gasset, como había venido haciendo durante toda su trayectoria intelectual continuó aportando una contribución sustancial al pensamiento europeísta como supuso su libro Meditación sobre Europa... ${ }^{4}$ La vida académica española a traves de todos estos medios contribuyó considerablemente a despertar el interés por la nueva Europa e indujo a reflexionar sobre la infuencia que podía ejercer sobre España, aunque para evitar confrontaciones con las autoridades evitó comentar sobre los problemas politicos que el régimen de Franco tendría para participar en ella.

La facción católica del régimen de Franco desempeñó un papel importante en la difusión del europeísmo desde la perspectiva franquista. Con la llegada de Alberto Martín Artajo y varios católicos vinculados a la Asociación Católica Nacional de Propagandistas (ACNP) al gobierno se comienzan a establecer contactos con circulos católicos y democristianos europeos. Son precísamente los católicos los que crean la primera organización europeísta española de corte político y la única que se mantiene fiel a los ideales franquistas durante toda su existencia, el Centro Europeo de Documentación e Información (CERI).

El CERI fue fundado en 1952 por Alfredo Sanchez Bella, a la sazón director del Instituto de Cultura Hispánica, y a pesár de su teórica independencia, recibió financiación del ministerio de Asuntos Exteriores. Entre sus miembros destacaban influyentes personalidades del régimen, como José Ignacio Escobar, marqués de Valdeiglesias o conocídos católicos, como Joaquín Ruiz Gimenez, el diplomático Gonzalo Fernández de la Mora o Manuel Fraga Iribarne los cuales utilizaron al CERI como fórmula para mantenerse en contacto con los circulos católicos y conservadores en Europa y al mismo tiempo ganar apoyo internacional para el régimen. Su

José Ortega y Gasset, Meditación de Europa, Revista de Occidente, 1960. 
ideologia era ultraconservadora y católica apoyando la construcción de Europa basada en principios cristianos, y combinando su ferviente anticomunismo con la crítica al modelo democrático occidental ${ }^{5}$.

La mayoría de las actividades del CEDI tuvieron como fín discutir una alternativa a la construcción democrática de Europa. En 1954 el CEDI se reunió en el castillo de Zeil en Alemania con objeto de discutir los estatutos del Consejo de Europa y evitar que estos bloquearan el ingreso futuro de la España de Franco por el motivo de no satisfacer los requisitos democráticos necesarios. El CEDI también puso a Manuel Fraga al cargo de preparar un proyecto alternativo para Europa, apoyando la idea de una confederación de jefes de estado, preferentemente monarcas, con una cámara alta. Al margen de la misión europeista del CEDI, también cumplía un importante fín diplomático ya que mantenía a la cúpula franquista en contacto con las élites conservadoras europeas, y era particularmente útil a la hora de fomentar las relaciones con Alemania. Por esta razón el ministro de Asuntos Exteriores Martín Artajo siempre se mostró dispuesto a apoyarlo; por el contrario, su sucesor Fernando María Castiella, nunca consideró el CEDI como una pieza útil de la diplomacia española, lo que provocó su decadencia a partír de $1957^{6}$.

El otro gran núcleo del europeismo español en los años cincuenta fue la Asociación Española de Cooperación Europea (AECE), fundada en 1954, en Madrid. Estaba vinculada al Movimiento Europeo, del cual siempre recibió su apoyo y consejo. Los primeros tres presidentes de la asociación fueron Francisco de Luis, José Yanguas Messía y José María Gil Robles y el puesto de secretario fue ocupado por Fernándo Alvarez de Miranda. En su manifiesto fundacional declaraba que sus fines eran:

"promover el estudio y la divulgación de la cooperación entre los pueblos de Europa como el medio más adecuado para garantizar una estabilidad social y una paz duradera,basadas en un orden internacional cristiano, en la justicia social y mejor aprovechamiento de los factores económicos"? ?.

La AECE originalmente tenía fuertes vínculos con la ACNP y muchos de sus miembros eran acerrimos conservadores o simpatizantes de la ideología democristiana, como Gonzalo Fernández de la Mora o Alfonso Osorio respectivamente, aunque gradualmente comenzó a incorporar a

5 Petra María WEBER, El CEDI, promotor de occidente cristiano y de las relaciones hispañoalemanas en los años cincuenta, Hispania, 1994, págs. 1.077-1.103.

Ibidem, pág. 1.091.

Javier Tusel.L, La oposición democrática al régimen de Franco, Barcelona, 1977, pág. 387. 
representantes de ideas liberales o incluso socialistas. En relación con el concepto de Europa la AECE experimentó una evolución similar. El 5 de julio de 1959, con ocasión del ingreso de España en la OECE, la AECE hizo sus primeras declaraciones de europeísmo democrático y federalista, pidiendo una homogeneidad política de los pueblos que forman la Unión Europea, sobre bases comunes de respeto al Estado de Derecho, a las libertades democráticas recogidas en la Convención Europea de Derechos del Hombre, y una distribución de la riqueza basada en la superior dignidad del trabajo ${ }^{8}$. De esta manera, una sociedad que nació con el beneplácito de los círculos franquistas se convertiria en poco tiempo en la más importante representante del pensamiento europeísta anti-franquista.

Otro importante centro de actividad europeista en este periodo, y este ya cláramente opuesto al régimen, fue el seminario de derecho político de la Universidad de Salamanca, dirigido por el catedrático socialista Enrique Tierno Galván. En diciembre de 1955 el profesor Tierno Galván publicó un artículo bajo el título de "doce tesis de funcionalismo europeo", en el que anunció la fundación de la Asociación por la Unidad Funcional Europea. Esta asociación estaba formada por jovenes profesores universitarios que compartían los mismos principios políticos: la defensa de la libertad, la democracia y el europeísmo. Por funcionalismo se referían a un método racional de definición del sistema político ideal, tomando la unificación de Europa como el fín a perseguir ${ }^{9}$.

La nueva asociación también comenzó a publicar una revista europeísta en 1956, "Europa a la vista», pero fue clausurada por el gobierno tras su tercera edición y, poco después, en 1960 Tierno Galván fue obligado a abandonar el país debido a sus actividades de oposición. Al calor de las revueltas universitarias experimentadas en 1956 una serie de pequeños grupos ilegales fueron fundados por estudiantes y profesores, con el fín de apoyar la democratización tales como la Agrupación Socialista Universitaria, la Unión Democráta Cristiana o el grupo monarquico Unión Española. Muchos miembros de estos grupos no habian participado en la Guerra Civil Española ni tenían contactos con la oposición democrática en el exilio. Sin embargo se expresaban en términos europeistas muy convencidos. Como lo describe el profesor Tierno Galván:

"toda actividad política anti-Franquista durante estos años tenía un caracter europeo. España era Europa en el sentido de que era anti-franquista. Europa

Fernándo Álváfiez de Miranda, Del contubernio al consenso, Barcelona 1985, pág. 26.

Enrique Tierno Galvan, Cabos sueltos, Barcelona 1981, págs 204-5. 
representaba para nosotros una ventana abierta que nos permitía soñar con la democracia» 10 .

El grupo monárquico Unión Española también utilizaría el europeísmo como fórmula para propugnar la monarquía constitucional. Por ejemplo a finales de 1961, poco despúes de la boda del príncipe don Juan Carlos, su presidente Joaquín Satrústegui subrayó la importancia de los factores políticos en el proceso de integración a Europa.

"Sí nuestro sistema - ya lo ha confesado nuestro régimen explícitamente- no puede integrarse en Europa es por razones políticas; si España, por este camino esta abocada al más triste aislamiento, lógico es que sostengamos que la Monarquía haya de ser en el orden político decidídamente europea, entre otras razones para poderio ser,también, en el orden económico, requisito indispensable del bienestar propio de un país occidental" ".

El europeísmo pronto comenzó a ser un factor unificador dentro de los distintos grupos que existián en la oposición interior al régimen. Una importantísima labor en pro de la unificación de todas las fuerzas políticas bajo el europeismo fue hecha por Manuel Giménez Fernández, un democristiano que propugnaba los valores de la democracia cristiana defendidos en Europa, no reaccionarios y basados en la democracia y la justicia social. Esta ideología le llevó a crear la Izquierda Democrática Cristiana en 1959. Este grupo hizo los primeros intentos de coordinación entre la democracia cristiana y el partido socialista. Los dos grupos iniciaron conversaciones en agosto de 1959, acordando un plan para unificar a toda la oposición democrática bajo los directivas de rechazo a la violencia, democracia y europeísmo ${ }^{12}$.

El europeísmo fue un elemento fundamental en la cultura política de la oposición en el exilio. Para ellos el europeísmo no sólo era la base de su pensamiento político, sino también un mecanismo para manifestar su oposición al régimen de Franco ante la comunidad internacional. El hecho de que la democracia fuera una condición sine qua non para la participación en el proceso de integración europea permitió a la oposición democrática en el exilio presentar al régimen de Franco como el gran obstáculo para que España pudiera desempeñar el papel que le corresponde en Europa.

\footnotetext{
10 lbidem. pág. 131.

$"$ TUSELL, La oposición., pág. 346.

1. Javier TUSELL, Gimenez Fernández, precursor de la democracia española, Mondiadori 1990 , pág. 275.
} 
La contribución más importante a la actividad europeísta en el exilio la hizo sin duda el político y escritor Salvador de Madariaga, seguido por Enrique Adroher Gironella, quienes habian sido las únicos representantes de España en la conferencia de Ginebra en 1948, en la cual se creó el Movimiento Europeo. Aparte de su papel como presidente del Consejo Español del Movimiento Europeo, Madariaga fue también miembro del Comite Permanente Ejecutivo del Movimiento Europeo, presidente de su Comisión Cultural, miembro del Consejo Administrativo del Colegio de Europa en Brujas, y presidente de la Liberal Internacional. Adroher-Gironella fue secretario del Consejo Español del Movimiento Europeo al igual que sectretario del Movimiento Socialista por los Estados Unidos de Europa ${ }^{13}$.

Madariaga llevó a cabo varios intentos con el fin de unificar la oposición bajo los lemas del anti-franquismo y el europeísmo. El Movimiento Europeo decidió establecer consejos de exiliados para países que padecían dictaduras y Madariaga aprovechó la oportunidad para establecer una oposición anti-franquista con una fuerte plataforma europea.

Los socialistas españoles en el exilio tanto los del PSOE como los de la rama sindicalista UGT combinaron una intensa campaña anti-franquista con el europeísmo en distintos foros: los partidos socialistas y sindicatos europeos, las instituciones europeas y el Movimiento Europeo. En un principio el europeísmo apareció como una baza útil para la actividad anti-democrática, basada en que la naturaleza del régimen de Franco era un obstáculo para la plena integración de España en las organizaciones europeas. Sin embargo más tarde se convertiría en una base esencial de su pensamiento político. Interpretaron la integración europea como una alternativa supranacional democrática capaz de contrarestar la supremacía de las dos superpotencias. En relación con el concepto de Europa los socialistas españoles del exilio se sintieron atraídos por el concepto de la Europa supranacional como la mejor fórmula para el establecimiento de una Europa socialista, que tanto los socialistas franceses como los belgas propugnaban, al contrario del concepto más nacionalista, el de "Europea de las naciones", de integración europea que apoyaban el partido laborista británico y los socialistas escandinavos ${ }^{14}$.

Los dirigentes del régimen de Franco tardaron bastante en adoptar la retórica europeísta debido a que la hostilidad entre España y las democracias

13 Paul Preston, Salvador de Madariaga and the quest for liberty in Spain, Oxford University Press, 1986.

14 Abdón MATEOS, "España en la presencia internacional del socialismo español en el exilio", Espacio, Tiempo y Forma, 2, 1989. 
europeas se prolongó durante bastante tiempo. Con la creación de la Comunidad Económica Europea en 1957 se comenzó a evolucionar hacia líneas más europeístas. La CEE dividió al gobierno entre escépticos y europeístas. En el lado de los escepticos se encontraban el general Franco y el almirante Carrero Blanco, quienes como militares seguían atraídos por una economía lo más autosuficiente posible, y también el ministro sin cartera Pedro Gual Villalbi. En el de los europeístas se encontraban los principales representantes del llamado gobierno de los tecnócratas, el ministro de Comercio, Alberto Ullastres, el minsitro de Exteriores Fernando María Castiella, el ministro de Hacienda Mariano Navarro Rubio y el secretario general técnico de la Presidencia del Gobierno, Laureano López Rodó ${ }^{15}$.

Los tecnócratas que introdujeron a la economía española en el sistema de libre mercado también consideraron esencial no quedarse fuera de la Comunidad Europea. Y así, el 9 de febrero de 1962, el gobierno tomó la decisión de solicitar la apertura de negociaciones con la CEE, con el fín de encontrar una fórmula de asociación economica sin condicionamientos políticos ${ }^{16}$. Los tecnócratas por lo tanto introdujeron un europeísmo económico que fue tácitamente aceptado por el resto de la cúpula del régimen. Poco después de la solicitud Franco comentó en privado: "en el Mercado Común tenemos aseguradas nuestras exportaciones de productos agrícolas...no nos queda más remedio que incorporarnos a Europa» 17 , comenzando así a mostrar mayor interés por Europa. Carrero Blanco, a pesár de haber descrito el Mercado Común como un feudo de masones, liberales y demo-cristianos, emprendería también la senda europeísta ${ }^{18}$.

\section{EL ASCENDIENTE PODER DEL EUROPEÍSMO A PARTÍR DEL CONTUBERNIO DE MUNICH}

El congreso de Munich es el acontecimiento más importante del europeísmo español en la época de Franco y tuvo gran trascendencia para el futuro político de España. La idea de reunir a la oposición interior y exiliada bajo los auspicios de un acto europeísta la habían tenido presente varios miembros de la oposición durante algún tiempo. Salvador de

\footnotetext{
15 Lauerano Lopez Rodo, Memorias, Barcelona 1990, págs. 193-4.

16 Para una análisis sobre la solicitud a la Comunidad Europea ver María Teresa La Porte, La politica europea de Franco, 1957-1962, Eunsa, 1992.

17 Francisco Franco Salgado-Araujo, Mis conversaciones privadas con Franco, Barcelona, 1977, pág. 334.

18 López Rodó, Memorias, pág. 302.
} 
Madariaga sugirió la idea y la AECE organizó una semana europeísta en Mallorca en septiembre de 1961, la cual fue prohibida por el gobierno. Con ocasión del IV congreso del Movimiento Europeo, su presidente Maurice Faure invitó a miembros de la AECE y el Consejo Español del Movimiento Europeo a participar en él, el 7 y el 8 de junio de 1962, dónde tendrían ocasión de discutir ante autoridades europeas sobre el futuro de España y su papel en Europa.

En el congreso se reunieron un total de 118 representantes de la oposición interior y exiliada. Se aprobó un texto en el que se pedía el establecimiento de una auténtica democracia, asi como el reconocimiento de los derechos humanos, de las distintas comunidades nacionales y los partidos políticos, y se reiteraba la esperanza de que la evolución hacia estos puntos permita a España incorporarse a Europa de la cual forma parte esencial ${ }^{19}$.

El mayor logro de este congreso fue que una serie de grupos políticos españoles a quienes sólo les unía su oposición al régimen de Franco se pusieran de acuerdo sobre cual debía de ser el futuro de España. También se logró que el europeísmo se convirtiera en el punto de encuentro de toda la oposición democrática. Tal era la importancia del europeísmo que el partido comunista español, que por no ser europeísta no había sido invitado a participar, decidió enviar dos observadores ${ }^{20}$.

La represión con la que el régimen reaccionó al congreso de Munich, bautizandolo como el contubernio de Munich, tuvo un efecto muy negativo sobre las perspectivas de su política europea. El hecho de que pocos meses después de haber solicitado la asociación a la CEE, el régimen reprimiera severamente a unos españoles que se habian reunido para discutir el futuro de España en Europa probaba el poco interés que tenía en evolucionar hacia la democracia, y que su europeísmo respondía únicamente a intereses económicos.

El llamado milagro económico español de los años sesenta tuvo mucha repercusión sobre el europeísmo español. España se convertia en la novena potencia industrial con los cambios socio-económicos que ello conlleva. El régimen consideró que estos cambios le afianzarían en el poder, sin embargo tuvo el efecto contrario. A medida que el nivel socio-económico español se

\footnotetext{
Joaquin Satrustegul (edit.), Cuando la transición se hizo posible. el contubernio de Munich. Madrid, 1993, pág. 108.

20 Gregorio MoRAn, Miseria y grandeza del Partido Comunista de España. Barcelona. 1990. págs. 353-54
} 
homologaba con el de Europa, los españoles no sólo fueron expuestos a la forma de vida de Europa occidental, sino que comenzaban a admirar sus instituciones y cultura política. El resultado de este fenómeno es que muchos que habían apoyado al régimen por los logros económicos que había traído comenzaron a verlo como un obstáculo para el futuro del país.

El europeísmo se convirtió en una nueva moda, compartida por todos los españoles, aunque interpretada de diferentes maneras dependiendo de la ideología e interés que hubiera tras el término. El régimen persistía con su europeismo económico. El embajador ante la Comunidad Europea, Ullastres, declararía en 1969 que la integración en la CEE era un asunto exclusivamente económico a plazo corto y sólo político a largo plazo, y que de momento lo prioritario era el desarrollo económico del país. El hecho de que se reconociera que a largo plazo habría que plantearse la integración en al ámbito político constituía una concesión importante por parte de este representante del régimen ${ }^{21}$. Sin embargo, el europeísmo económico ya ni siquiera convencía a los círculos económicos y empresariales, que comprendian que sin evolución política no había posibilidad de avanzar hacia la integración.

La política europea franquista creó disidentes, incluso dentro de sus filas. Son notorios los casos de algunos miembros de la élite franquista que decideron pasarse a las líneas de la oposición al sentirse incómodos con el papel de la España de Franco en Europa. Los ex-ministros José Larraz y Joaquín Ruiz Giménez son dos buenos ejemplos, pero el más significativo es el de Jose María de Areilza, conde de Motrico. Areilza había sido un destacado miembro de la élite franquista desde la guerra civil, y desempenó una brillante carrera diplomática como embajador. Su ideología evolucionó desde un acérrimo franquismo hacia el liberalismo monarquico. Cómo embajador en París propugnó la reforma política para garantizar el éxito de la politica europea. Sin embargo, decepcionado por los acontecimientos del congreso de Munich decidió dimitir de su cargo en 1964. Tras su dimisión se dedicó a trabajar por el establecimiento de una monarquía constitucional en el consejo privado del conde de Barcelona, recordando constantemente a los españoles que sín democracia España nunca desempeñaría el papel que le correspondía en Europa ${ }^{22}$.

Un factor importante a la hora de difundir el europeismo de la oposición democrática en los años sesenta fue la introducción de una nueva ley de

Salvador Paniket, Conversaciones en Madrid, Barcelona 1970, pág. 25-28.

José Maria IJ ARFILzA. Cronica de libertad. Barcelona, 1985. 
prensa en 1966, por la cual la censura previa desaparecía. La oposición interior se aprovechó de esta circunstancia para publicar sus ideas sobre la democracia en publicaciones como Arbor, El Ciervo y ante todo Cuadernos para el Diálogo. Esta última la dirigía el ex-ministro Joaquín Ruiz Gimenez, que se había convertido en un critico implacable del régimen. Prácticamente todas las ediciones de esta revista mensual hacían alguna referencia al proceso de integración europea, declarándose en favor de un concepto supranacional de Europa y criticando severamente al régimen por no reconocer el hecho de que sin democracia el ingreso en la Comunidad Europea era imposible ${ }^{23}$.

La firma del tratado preferencial entre España y la Comunidad Europea, el 29 de junio de 1970, constituye un momento culminante en la confrontación entre los distintos conceptos de europeísmo. El gobierno y la prensa franquista interpretaron este tratado como un éxito para la diplomacia española, que desafíando a la oposición socialista había conseguido poner el primer pie en la Europa comunitaria mediante un acuerdo económico en términos muy beneficiosos para la parte española, y sin hacer ningúna claudicación en el ámbito político. A pesár de ser un mero tratado comercial sin ningún contenido político, la España oficial consideró que Franco se apuntaba un tanto político en el frente europeo. Tampoco veían ningún problema a la hora de avanzar hacia un mayor grado de integración en la Europa comunitaria sín que ello supusiera ningún cambio de sistema político ${ }^{24}$.

La oposición interior reaccionó como en otras ocasiones pidiendo el cambio político. El 9 de marzo de 1970, la dirección de la AECE, declaró que el acuerdo presentaba aspectos positivos con respecto a la vocación europeísta de España y sus intereses económicos, sin embargo dejaba a un lado el aspecto final de la incorporación de España como miembro de pleno derecho, que requeriría la transformación en un estado democrático, por lo que entendian una organización política liberal ${ }^{25}$.

El acuerdo indignó a la oposición democrática, aunque optó por restarle importancia, alegando que ni siguiera suponía un éxito en el ámbito económico. Para el periódico El Socialista, el acuerdo no contribuía al progreso económico español ni mucho menos, sino tan sólo suponía una serie de concesiones arancelarias modestas con las que la CEE compensaba al régimen del hecho de que no pudiera optar a la asociación ${ }^{26}$. El

23 Ver por ejemplo, Cuadernos para el Díalogo, febrero 1967.

24 ABC, La Vanguardia Española, 30-6-1970.

25 Álvarez de Miranda, Del contubernio, pág. 61.

26 El Socialista, España dentro de Europa, 8-4-1970. 
Consejo Español del Movimiento Europeo hizo un comunicado mediante el cual señalaba que el acuerdo preferencial no era un primer paso hacia la integración en la CEE ${ }^{27}$.

Los acontecimientos que siguieron tras el tratado preferencial tanto en el ámbito económico como político no hicieron sino reforzar el europeísmo de la oposición interior y la del exilio. Tras la ampliación de la Comunidad Europea de seis a nueve miembros en 1973,se hizo necesaria la re-negociación del tratado preferencial. Un contexto europeo, poco favorable hizo dificil esta negociación, pero, por otro lado, también la dificultó la situación política española, donde la represión crecía ante el evidente declive en que entraba el régimen. Mientras tanto incrementaban en Europa las presiones pidiendo el abandono de negociaciones con la España de Franco.

El fracaso de la política europea fue otro motivo más que agitó a la oposición durante los últimos años del régimen. A pesár del incremento de la represión, el europeísmo siguió siendo un tema sobre el que el gobierno permitía mayor grado de discución. Por lo tanto, el tema de Europa fue utilizado constantemente para organizar actividades anti-franquistas. Ante la urgente necesidad de dar soluciones para el futuro los grupos de oposición también comenzaron a establecer contactos con políticos e instituciones europeas con el fín de contar con su cooperación ante el inminente cambio de sistema político.

La AECE fue de nuevo el grupo más activo en el campo europeísta. Por ejemplo, durante el décimotercer congreso del Movimiento Europeo en 1972, que coincidió con el décimo del congreso de Munich, la AECE aprovechó la ocasión para reiterar las conclusiones a las que había llegado diez años antes e insistir en la necesidad de que las instituciones es. pañolas evolucionaran hacia la Comunidad Europea ${ }^{28}$.

Al calor de la actividad europeísta surgía un nuevo grupo de oposición, con gran trascendencia no sólo en el pensamiento europeísta sino particularmente en la transición a la democracia: el grupo Tácito. Tácito fue fundado en mayo de 1973, y la edad, ocupación y perfil social de sus miembros son quizas los elementos que mejor puedan definirla. La mayoría de ellos tenía entre treinta y cuarenta años y pertenecía a los grupos de élite de la administración franquista o tenía fuertes vínculos con ella. Muchos habian sido miembros de la Asociación Católica Nacional de AECE.

Consejo Federal Español del Movimiento Europeo, Declaración. Paris, 22-6-1970. Archivo Álvarez de Miranda, Del contubernio, pág. 67 
Propagandistas o la AECE y solian simpatizar con la ideología democristiana. Su objetivo era una transición pacífica hacia la democracia, estando convencidos de que tal fín sólo era posible mediante la reforma desde el interior ${ }^{29}$. Tras la muerte de Carrero Blanco, Tácito expresaba su preocupación por la relación con Europa en un artículo en el diario Ya:

\begin{abstract}
"para nosotros la tarea principal en la proyección exterior de nuestro país es la integración en la CEE. Estamos preocupados por las consecuencias de un asilamiento de los Nueve a medida que estos adquieren mayor cohesión. Todos sabemos que la Comunidad y varios ministros de exteriores se oponen al ingreso por razones políticas. Qué medidas se van a tomar? Hay realmente intención de homologar nuestras instituciones con las de la Comunidad? ${ }^{30}$.
\end{abstract}

La actitud del Partido Comunista de España hacia la Comunidad Europea da una idea de la importancia que tenía el europeísmo para toda la oposición a la hora de encauzar el futuro de España. EI PCE como todos los partidos comunistas de obediencia soviética no sólo no eran europeístas sino que consideraban la CEE como una estrategia capitalista para proteger sus intereses. Por esta razón, el PCE fue el único partido de la oposición que no fue invitado al congreso de Munich. Sin embargo, durante los años sesenta, su lider Santiago Carrillo, comenzó a distanciarse de la línea soviética y a simpatizar con el termino eurocomunismo, un comunismo adaptado a Europa occidental. En el octavo congreso del PCE en el exilio, celebrado en París en 1972. una de las decisiones más importantes que se tomó fue apoyar la integración de España en la Comunidad Europea una vez establecida la democracia. Las razones esgrimidas para este cambio fundamental fueron una mezcla de necesidades económicas y estrategia política. A pesár de ser un movimiento capitalista, la integración económica europea era una realidad que no podía ser ignorada. Esta era la zona natural de las exportaciones españolas, por lo tanto quedarse fuera dañaría a la economía y a la clase trabajadora ${ }^{31}$.

Fue precisamente esta evolución hacia posiciones compatibles con las del resto de la oposición democrática la que hizo posible que el PCE pactara la creación de la Junta Democrática con el disidente monárquico

Charies T. Powell, «The Tácito group and the Spanish transition to democracy.. Frances Lannon \& Paul Preston. (eds). Elites and Power in Twentieth Century Span. Essays in honour of Sir Raymond Carr. Oxford

Ya. Coodenadas de la politica exterror, 30-6-1973

Mundo Obrero. Resoluciones del XVIII Congreso. 
Rafael Calvo Serer en agosto de $1975^{32}$. Este último, desde su exilio en Paris, ejercía una dura oposición al franquismo, a menudo con gran contenido europeísta.

Los sucesos que siguieron a la muerte de Carrero Blanco no hicieron sino empeorar las relaciones con la Comunidad Europea hasta el punto de invalidar los exitos de la diplomacia franquista en el frente europeo. Los medios europeos comentaban con decepción la represión del régimen y el inevitable deterioro de las relaciones con Europa. Tras las ejecuciones de septiembre de 1975, todos los embajadores de Europa occidental, a excepción del de Irlanda, abandonaron Madrid. De esta forma Franco moría en un ambiente de hostiidad entre España y Europa similar al experimentado en los años de la post-guerra mundial. El europeísmo económico nunca triunfaría sin un europeísmo en el ámbito político también.

\section{EL EUROPEISMO COMO FACTOR CONCILIADOR DE LA POLÍTICA ESPAÑOLA}

Durante la transición democrática una de las tareas más urgentes fue el recuperar la confianza de las democracias europeas y reanudar las relaciones con la Comunidad Europea. Fue por esto por lo que gobierno y oposición pugnaron por ganarse el apoyo europeo y por lo que el europeísmo desempeñó un papel clave en la transición.

En su primer discurso ante las Cortes españolas, como rey de España, don Juan Carlos I se expresó en términos muy europeístas:

"La idea de Europa seria incompleta sin una referencia a la presencia del hombre español y sín una consideración del hacer de muchos de mis predecesores. Europa deberá contar con España pues los españoles somos europeos. Que ambas partes asi lo entiendan y que todos extraigamos las consecuencias que se derivan es una necesidad del momento" ${ }^{33}$.

Un día antes de la coronación del rey Juan Carlos, su padre, el conde de Barcelona, quien era aun el jefe de la casa real lanzaba un comunicado en relación con el papel de la monarquía. Debería ser un poder arbitral e independiente, que fuera capaz de superar la Guerra Civil, consolidar una democracia pluralista basada en la justicia social, y la plena integración en

Santiago Carłrll lo, Memorias, Barcelona. 1993, pág. 600: Rafael Calvo Seren, Mis enfrentamientos con el poder. Plaza y Janés. 1978. págs. 251-252.

ABC. Mensaje del Rey, 22-11-1975. 
la Comunidad Europea. A excepción del heredero al trono austro-hungaro, Otto de Habsburgo, ningún otro monarca europeo hubiera incluido la integración en la Comunidad Europea entre los objetivos básicos de la monarquía. Don Juan que habia pasado gran parte de su vida en el exilio comprendía que la única manera de legitimar el papel de la monarquía en la España post-franquista era superando los traumas del pasado y servir a una sociedad moderna e igualitaria, y para este fín se consideraba que la integración en la Comunidad Europea era esencial ${ }^{34}$.

El nuevo gobierno pusó al frente del Ministerio de Asuntos Exteriores a un pilar del europeísmo, José María de Areilza. Nadie en España estaba mejor dotado que el conde de Motrico para la tarea de informar a Europa sobre los planes de democratización del gobierno. Areilza emprendió una gira por Europa en los primeros meses de 1956, informando a sus interlocutores que en el plazo de un año habría elecciones generales en España y que tras el establecimiento de la democracia se solicitaría su ingreso en la Comunidad Europea ${ }^{35}$. Estos planes fueron truncados por la política interior, en la que el gobierno, al frente de Arias Navarro, ignoraba los planes europeístas de Areilza, anclandose en la represión y el inmobilismo. Ignorar a Europa podía tener graves consecuencias. La recientemente fundada coalición de oposición Platajunta propugnaba la fórmula de ruptura pactada y presionaba a las instituciones europeas para que retiraran su apoyo del gobierno de España ${ }^{36}$. En estas circunstancias don Juan Carlos decidió retirar su confianza a Arias Navarro y cambiar de gobierno.

El nuevo presidente del gobierno, Adolfo Suárez, jamas había expresado el más mínimo pensamiento europeísta. Sín embargo, su gobierno fue bastante más europeísta que el anterior. Tuvo a dos miembros del grupo Tácito en puestos clave: Marcelino Oreja, en el ministerio de Asuntos Exteriores y Alfonso Osorio, en el ministerio de la Presidencia. Este gobierno comprendió que el anterior había fracasado por ignorar la dimensión europea y se propuso recobrar la confianza de Europa. Osorio muy en su papel cultivó la relación con el eurodiputado socialista Maurice Faure quién consiguió que el Parlamento Europeo volviera a apoyar al gobierno español, e impidiera la aprobación de una moción que proponia retirarle la confianza. A partír de ese momento, como Osorio comenta en sus memorias políticas "el gobierno tenía ganada la batalla en Europa" ${ }^{37}$.

34 Luis Maria ANSÓN, Don Juan, Plaza y Janés, 1994, pág. 408

35 José María D: ARIELI.ZA, Diario de un ministro de la monarquía, Barcelona, 1977.

36 El Pais, 12-5-1977.

37 Alfonso Osorio, Trayectoria política de un ministro de la Corona, Barceiona, 1987, pág. 216. 
Europa estuvo muy presente en las elecciones generales. La mayoría de los partidos habían contado con la colaboración de sus homólogos europeos e incluso habian recibido ayuda financiera. Los cuatro grandes partidos UCD, PSOE, PCE y AP al igual que los nacionalistas vascos y catalanes PNV y CIU incluyeron la integración en la Comunidad Europea como un objetivo prioritario en sus programas electorales.

El 22 de julio de 1977, poco más de un mes después de las elecciones generales el Consejo de Ministros del nuevo gobierno de la UCD anunciaba la intención de solicitar el ingreso de España en la CEE. En ese mismo día, el presidente Suarez se reunión con el lider del Partido Socialista Felipe Gonzalez, quien declaró a la prensa: "el PSOE apoya la soliticud de ingreso en la CEE» ${ }^{38}$.

Sería precísamente a un miembro del grupo Tácito, Marcelino Oreja a quien como ministro de Asuntos Exteriores le correspondió viajar a Bruselas el 26 de julio, para entregar en nombre de su gobierno, la solicitud española de plena integración en la Comunidad Europea. Al ponerse en viaje comentaría a la prensa: «la opción adoptada por el gobierno de solicitar el ingreso en la Comunidad Europea es auténticamente nacional» ${ }^{39}$.

Dos años después, tras el comienzo de las negociaciones oficiales entre España y la Comunidad Europea, el 27 de junio de 1979, se sometió a discusión el ingreso en la CEE en el Congreso de los Diputados. Tras intervenir el ministro para las relaciones con la Comunidad Europea, Leopoldo Calvo Sotelo y Marcelino Oreja pidiendo la aprobación del ingreso, la moción se aprobó por 285 votos a favor y sólo dos en contra. Una moción conjunta aprobada con el apoyo de todos los partidos: UCD, AP, PSOE, PCE al igual que los partidos nacionalistas CIU y el PNV, pondría remate al consenso europeísta ${ }^{40}$.

El apoyo unánime de todos los partidós políticos al ingreso en la CEE constituye un hecho insólito en Europa y prueba el importante papel que había desempeñado el europeismo en la historia reciente del país. Ni siquiera en los casos de los vecinos del sur de Europa, Grecia y Portugal donde la Comunidad Europea también había contribuido a su democratización se da el caso de este consenso europeísta ${ }^{41}$. Làexplicación de

El Pais, 23-7-1977.

Agence Europe, El Pais, 27-7-1977

Diario de Sesiones del Congreso de los Diputados, DSDC, 21, 27-6-1979, págs. 1.044-5.

Sobre la excepcionalidad del consenso europeista español ver la tésis doctoral de Berta Álvarez de Miranda, Los partidos políticos en Grecia, Portugal y España ante la Comunidad Europea: una explicación del consenso europeista español, Instituto Juan March, 1995. 
esta paradoja es que en España el europeísmo era punto de encuentro de fuerzas anteriormente enfrentadas. Para las élites conservadoras, para todos aquellos que habían apoyado al régimen de Franco el ingreso de España en la Comunidad Económica Europea simbolizaba el respeto a la propiedad y la empresa privada y la supervivencia de ciertos valores tradicionales en contra de aventuras revolucionarias izquierdistas. Para los grupos de la izquierda y todos aquellos que habían padecido persecuciones políticas o el exilio, la CEE suponía la democracia, las libertades civiles y políticas y el respeto a los derechos humanos, una garantía de que el fantasma de la dictadura sería al fin enterrado en España.

\section{CONCLUSIÓN}

El europeísmo desempeñó un papel fundamental en el pensamiento político de la España de Franco. El análisis de cómo veían los españoles su relación con Europa, y lo que Europa representaba, desvela una de las claves por la que tras la muerte de Franco el Movimiento Nacional es desmantelado y España se convierte en una democracia homologada en Europa. Fundamentalmente el europeísmo es sinónimo de dos cosas: la plena integración de España en Europa occidental y la democracia.

Durante el régimen de Franco surgen tres distintas interpretaciones del europeísmo:

El de la cúpula oficial del franquismo, es ante todo económico, y surge ante la realidad de que el progreso económico de España depende en gran medida de Europa y que por lo tanto se debe intentar el mayor grado de integración en la Comunidad Europea sin que esto suponga aceptar condiciones políticas. Sí, en un principio, este europeismo contribuyó a la popularidad del régimen, a la larga, le resultaría perjudicial, pues cualquier grado de integración mayor al del tratado preferencial con la CEE suponía también la integración política.

Otra forma de europeismo es el de la oposición reformista en el interior, principalmente representado por la AECE. Su actitud hacia hacia Europa era la de favorecer el mayor grado de integración en la Cornunidad Europea, pero eso sí pidiendo a la vez la democratízación del sistema para así hacer posible la plena integración de España en la CEE. La AECE y más tarde el grupo Tácito y otros personajes de la oposición interior fueron los principales responsables de la difusión de este mensaje a la opinión pública: la integración en Europa es igual a democracia. 
En tercer lugar está el europeísmo del los españoles en el exilio. Éste es el más radical. Suelen simpatizar con el concepto supranacional de integración europea que es el que da menor independencia política a los estados nacionales. Su actitud hacia el régimen de Franco es totalmente intransigente pidiendo a las instituciones europeas que España sea apartada de toda actividad europea hasta que dicho régimen desaparezca.

Durante la transición estos tres europeísmos se unen en uno. En la dificil coyuntura que supone la transición de la dictadura a la democracia el europeísmo es el único factor que no crea divisiones entre el gobierno y los distintos grupos de oposición, pues por razones de progreso económico o consolidación democrática, todos apoyan la integración de España en la Comunidad Económica Europea. Este consenso no se comprende sin examinar la evolución del europeísmo desde los años más difíciles de la España franquista, cuando Europa emerge como una solución a los males que acechan a la patria: el atraso económico, el aislamiento y la dictadura. 